\title{
AS CONTRIBUIÇÕES DO DIREITO CANÔNICO PARA O DIREITO ROMANO E SUAS INFLUÊNCIAS ATUAIS
}

\author{
CONTRIBUTIONS FROM CANONIC LAW TO ROMAN LAW AND ITS CURRENT INFLUENCES
}

José Antonio da Silva ${ }^{1}$

Submetido em: 17/04/2021
Aprovado em: 06/05/2021

e24208

\section{RESUMO}

Sabe-se que o direito e toda a humanidade ocidental sofreu ao longo de sua história influência da religião, sobretudo, do cristianismo. Hoje em dia, o direito canônico é restrito a religião, porém, suas contribuições ainda fazem parte da sociedade. Muito se fala sobre o Estado Laico, porém, nota-se uma confusão entre laicismo e laicidade, um Estado independente com um Estado antirreligioso. Fato é, que durante toda a história da humanidade os radicalismos sempre fizeram mal. Olhares maniqueístas pouco colaboram com a verdade. Atrelar a religião ao Estado como mandatório divino a quem governa parece um sistema fadado ao absolutismo. Estados confessionais têm sido duros com as outras religiões que não a do detentor do poder. Por outro lado, um Estado antirreligioso parece desconhecer a trajetória humana e sua relação com os valores metafísicos.

PALAVRAS-CHAVE: Direito canônico. Direito Romano. Estado Laico.

\begin{abstract}
It is known that the law and all western humanity has suffered throughout its history the influence of religion, above all, of Christianity. Nowadays, canon law is restricted to religion, however, its contributions are still part of society. Much is said about the Secular State, however, there is a confusion between secularism and secularism, an independent state with an anti-religious state. Fact is, that throughout the history of mankind radicalisms have always done harm. Manichaean looks do little to contribute to the truth. To tie religion to the State as a divine mandate to those who govern seems to be a system fated to absolutism. Confessional states have been harsh with religions other than the one in power. On the other hand, an anti-religious state seems to be unaware of the human trajectory and its relationship with metaphysical values.
\end{abstract}

KEYWORDS: Canon law. Roman law. Laic State.

\footnotetext{
1 Possui Licenciatura em Filosofia pela Faculdade Católica de Anápolis, Anápolis. GO, Sociologia pela Faculdade Paulista São José, São Paulo/SP, Bacharelado em Teologia pelo Centro Universitário de Juiz de Fora. Juiz de Fora, MG. Mestrado em Direito Canônico pela Pontifícia Universidade Gregoriana de Roma e Revalidado pela UCP - Universidade Católica de Petrópolis. Doutorando em Direito Canônico pela Pontifícia Universidade Católica de Buenos Aires. Atualmente é Integrante do Conselho Diretor da FUSVE - Fundação Educacional Severino Sombra, mantenedora da USS - Universidade Severino Sombra. Foi Coordenador do Curso de Teologia, Diretor de Ensino de Graduação e Reitor da mesma Instituição. É Sócio Efetivo da Sociedade Brasileira de Canonistas. Vigário Geral da Diocese de Valença e Pároco de Vassouras. Juiz Eclesiástico das Dioceses de Valença e Barra do Piraí/Volta Redonda. Docente da Universidade Santa Úrsula e Universidade de Vassouras. Tem experiência nas áreas de Teologia, Filosofia e História, com ênfase em Direito Canônico, Teologia Pastoral, Liturgia, Educação, Religião, História e Gestão de Projetos. Coordenou a implantação do Projeto CENTRO DE MEMÓRIA DA PARÓQUIA DE NOSSA SENHORA DA CONCEIÇÃO E DA IRMANDADE NOSSA SENHORA DA CONCEIÇÃO DA FREGUESIA DE VASSOURAS, trabalho apresentado no 4ำ Congresso de Pesquisa e Extensão do UNIPTAN, Centro Universitário Presidente Tancredo de Almeida Neves, na cidade de São João Del-Rei, MG. Tem vários artigos publicados em Revista Científica da PUC/SP, Revista Interdisciplinar Núcleo do Conhecimento. É o Editor responsável da Revista O Semeador. É Avaliador Ad Hoc da Revista Multidisciplinar de Humanidades Mosaico, da Universidade de Vassouras. Publicou seis livros, sendo dois como organizador.
} 


\section{RECIMA21 - REVISTA CIENTÍFICA MULTIDISCIPLINAR ISSN 2675-6218}

AS CONTRIBUIÇÕES DO DIREITO CANÔNICO PARA O DIREITO ROMANO E SUAS INFLUÊNCIAS ATUAIS
José Antonio da Silva

\section{INTRODUÇÃO}

Sabe-se que o direito e toda a humanidade ocidental sofreu ao longo de sua história influência da religião, sobretudo, do cristianismo. Hoje em dia, o direito canônico é restrito a religião, porém, suas contribuições ainda fazem parte da sociedade.

Muito se fala sobre o Estado Laico, porém, nota-se uma confusão entre laicismo e laicidade, um Estado independente com um Estado antirreligioso. Fato é, que durante toda a história da humanidade os radicalismos sempre fizeram mal. Olhares maniqueístas pouco colaboram com a verdade. Atrelar a religião ao Estado como mandatório divino a quem governa parece um sistema fadado ao absolutismo. Estados confessionais têm sido duros com as outras religiões que não a do detentor do poder. Por outro lado, um Estado antirreligioso parece desconhecer a trajetória humana e sua relação com os valores metafísicos.

Muitos conceitos jurídicos atuais nasceram tanto em Roma como na Grécia e tiveram como base o direito canônico, originado das verdades religiosas. Há muito no nosso sistema jurídico herdado dos valores cristão. Falamos em ética, em honestidade, em convívio harmonioso, em respeito, em proteção às pessoas, em cuidar dos que são mais vulneráveis, mas as religiões há muito vêm insistindo nessa prática.

Se, para grande parte das religiões, esses conceitos nascem do fato de sermos todos irmãos, para o direito, vêm do fato de sermos todos cidadãos. Os tempos, em tese, foram nos acrescentado luzes para que nossas relações fossem diferentes. Não há um cidadão de primeira e outro de segunda ou terceira categoria. São todos cidadãos. Isso nos parece ter nascido de um mandamento cristão, "Amai ao próximo como a si mesmo".

Valores religiosos influenciando o Estado nos princípios que nos levam a validar cada vez mais de nossa Constituição Federal: "a dignidade da pessoa humana". E o Estado garantindo que no bem-estar social, no direito à felicidade, cada qual escolha se quer ou não fazer parte de uma religião, e daquela religião que melhor o ajude a desenvolver as suas melhores relações consigo e com o outro.

À filosofia do direito, portanto, interessa a questão das relações entre Estado e Religião, entre o poder temporal e o espiritual. Nesse âmbito se enfrentam questões sobre a legitimidade do poder estatal e do Direito além de que, a liberdade religiosa, hoje internacionalmente reconhecida como um direito humano, tem diversas abordagens e consequências.

Diversos institutos e fontes do direito tem sua origem no direito canônico, dentre eles, pode-se citar, a teoria da pessoa jurídica, o negócio jurídico, o direito processual e o instituto do matrimônio, fora outras influências no direito civil.

No entanto, importante destacar que existe, portanto, entre Igreja e Estado entre religião e política, uma separação lícita e necessária - a laicidade - e uma separação indiferentista e insustentável: o laicismo. Porque a laicidade é prerrogativa consubstancial à "ordem autônoma" do 


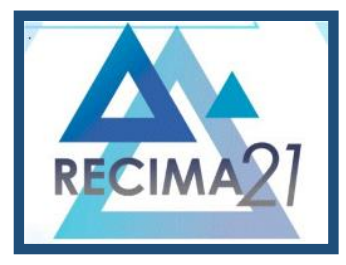

\section{RECIMA21 - REVISTA CIENTÍFICA MULTIDISCIPLINAR ISSN 2675-6218}

Estado e o laicismo supõe a ruptura arbitrária e artificial do elo essencial que une toda a atividade com a "ordem teonômica". Na verdade, a separação saudável entre Estado e religião é entendida como condição à plena liberdade religiosa, já que Estados confessionais tendem a restringir a prática de outras religiões.

\section{DIREITO CANÔNICO}

O Direito Canônico nasce pela necessidade e com o propósito de organizar e manter a ordem de acordo com os anseios da vida em comunidade e dos preceitos divinos estabelecidos e divulgados pela Igreja Católica. Muitos dos institutos existentes no direito ocidental moderno foram inspirados ou copiados do Direito Canônico, pela funcionalidade que este revela para com os fins a que foi criado'.

Tão soberano como o Estado é a Igreja dentro de seus âmbitos de atuação, carecendo assim de um eficaz aos seus propósitos e às necessidades nascidas das relações sociais manifestadas entre seus seguidores (no caso da Igreja) ou governados (no Estado) ${ }^{2}$.

Por isso, o direito estatal e o eclesiástico colaboram-se mutuamente, haja vista que muitas das manifestações sociais reveladas no Estado são de interesse religioso e vice-versa, como exemplo, o casamento e a instituição da família.

Há outra série de conceitos e institutos jurídicos criados pelo Direito Canônico e aderidos pelo direito secular ocidental. Tem-se, por exemplo, a teoria da pessoa jurídica, que não foi, de forma alguma, construída pelos romanos, mas pela Igreja, que sempre se enxergou como uma universalidade e, em certa altura da Idade Média, preocupou-se em enfrentar problemas relacionados a patrimônio comum, representação e responsabilidade.

Assim, foram criados alguns princípios: autonomia da associação (direito de corporação); direito de a corporação jurisdicionar sobre seus componentes; direitos de os membros da corporação serem ouvidos sobre pena de nulidade de alguns atos; ideia de patrimônio comum entre os membros da corporação, ideia de delito coletivo, se este fosse cometido pela maioria dos membros da corporação. Contudo, se o líder corporativo ou o governo de determinado local cometesse crime, somente ele seria julgado e não todos os corporativistas ou governados.

\subsection{Igreja e Estado: Idade Média}

A compreensão da justiça na Idade Média tem engendrado uma série de questões para o entendimento do espaço urbano medieval. Então, podem ser propostas as seguintes questões:

\footnotetext{
1 LOURENCINI, Antônio Rogério. O direito canônico e a formação do direito ocidental moderno: Dos fundamentos do direito canônico à sua geral influência no ordenamento jurídico estatal, mormente no direito de família (matrimônio). Revista Jus Navigandi, ISSN 1518-4862, Teresina, ano 19, n. 3919, 25 mar. 2021. Disponível em: <https://jus.com.br/artigos/27059>. Acesso em: 28 abr. 2018.

2 BITTAR, Eduardo C. B. (Org.). História do direito brasileiro. 3.ed. São Paulo: Atlas, 2013. (e-book)
} 


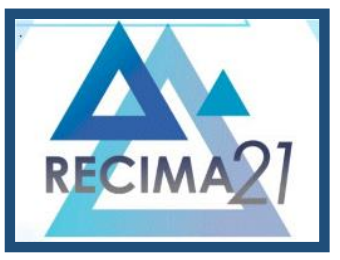

\title{
RECIMA21 - REVISTA CIENTÍFICA MULTIDISCIPLINAR ISSN 2675-6218
}

como compreender a cidade medieval em um universo que possui uma essência rural? Como os medievalistas têm compreendido isso? Como a cidade medieval tratava a questão sanitária?

Castells sugere em seu estudo que a cidade medieval se desenvolve a partir do contexto político, econômico e social medieval. A constituição de mercado, concomitantemente à criação de novas instituições político-administrativas, são características desse desenvolvimento ${ }^{3}$. Além disso, ele defende a tese que tem como base a ideia de que a formação das cidades na Idade Média expressou a luta da burguesia em face ao feudalismo e a um suposto poder central. No entanto, o autor em questão diz que o prosseguimento da trajetória das cidades, dependeu das relações que aquelas contraíam com o mundo medieval como um todo. Nas palavras do próprio estudioso:

\begin{abstract}
Como a cidade medieval representa a libertação da burguesia comerciante na sua luta para emancipar-se do feudalismo e do poder central, sua evolução será bem diferente conforme os laços estabelecidos entre burguesia e nobreza. Assim, onde estes laços foram estreitos, as relações entre a cidade e o território circunvizinho, dependendo dos senhores feudais, organizaram-se de modo complementar. E, ao inverso, o conflito destas classes ocasionou o isolamento urbano 4 .
\end{abstract}

O estudo sobre a cidade na Idade Média tem sido beneficiado por questões frequentemente postas pelos historiadores. Jacques Le Goff é um deles. E, segundo José D’Assunção Barros, o medievalista francês propõe três questões fundamentais:

\begin{abstract}
O estudo da Cidade Medieval tem se aberto no século XX a algumas questões a algumas questões primordiais. Três delas, para dar um primeiro exemplo foram formuladas por Jacques Le Goff nos seguintes termos: (1) Como se integra a cidade no mundo de produção feudal? (2) De onde provém, antes disto, a formação e o desenvolvimento do urbanismo medieval? (3) O que representa a cidade, por fim, para o cristianismo medieval - funcionando este simultaneamente como religião e como ideologia dominante ${ }^{5}$.
\end{abstract}

As questões aventadas pelo historiador francês sugerem que a historiografia medieval na atualidade não consegue desvincular o estudo da cidade do mundo medieval como um todo. Assim, a cidade na Idade Média mantém uma autonomia no que diz respeito à organização política, à econômica e à social, mas não está dissociada do mundo rural e feudal. A burguesia citadina e os demais grupos sociais não se colocavam em confronto com o mundo rural no período medieval ${ }^{6}$.

A Antiguidade clássica foi marcada pela presença das cidades que atestaram 0 desenvolvimento político, econômico e cultural. Já no período que marca o fim do mundo antigo e

\footnotetext{
${ }^{3}$ CASTELLS, Manuel. A Questão urbana. 3.ed. Rio de Janeiro: Paz e Terra, 2006, p. 43.

4 CASTELLS, Manuel. A Questão urbana. 3.ed. Rio de Janeiro: Paz e Terra, 2006, p. 44.

5 BARROS, José D’Assunção. A Cidade Medieval: os grandes debates historiográficos. Rio de Janeiro:

CELA, 2003, p. 11.

${ }^{6}$ BARROS, José D’Assunção. A Cidade Medieval: os grandes debates historiográficos. Rio de Janeiro: CELA, 2003.
} 


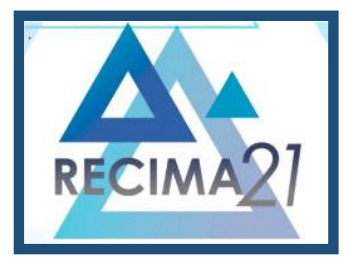

\section{RECIMA21 - REVISTA CIENTÍFICA MULTIDISCIPLINAR ISSN 2675-6218}

início do mundo medieval, no entanto, ocorre a intensificação do processo de ruralização que determinou a história da Idade Média Ocidental ${ }^{7}$.

Embora preso às necessidades materiais, tanto o homem quanto a mulher tinham uma enorme preocupação com a chamada vida espiritual que marcava o cotidiano e as diversas manifestações culturais. Pode-se concluir, também, que a cultura erudita e a cultura popular do período medieval tiveram uma forte presença de valores religiosos, porque, acrescente-se, as manifestações religiosas e espirituais estiveram presentes na cultura citadina do mundo medieval. A presença dessas manifestações, entretanto, entrou em conflito com os novos valores culturais do meio urbano e ensejaram novas representações da vida e do cotidiano.

Noções como cotidiano, imaginário e mentalidades foram desenvolvidas pelos historiadores medievalistas, renovando, de modo contundente, a historiografia em relação ao ocidente medieval. Com isso, o exame do cotidiano e da cultura medieval, tanto no meio rural, quanto no meio urbano, foram agraciados com novos objetos e temas que convergiam no geral para as manifestações da chamada cultura popular, ainda que a cultura erudita não fosse preterida ${ }^{8}$.

A religiosidade medieval tratava e compreendia os assuntos materiais por via do sagrado. Daí, as peregrinações e os movimentos cruzadistas que foram impulsionados pela mentalidade cristã obcecada pelo medo do pecado e do diabo. A Igreja Católica, que procurava deter o monopólio do sagrado, teve um papel importante naquele período e no desenvolvimento do direito canônico.

A trajetória da Igreja no período medieval foi determinante pela presença de dois protótipos engendrados no mundo antigo: "a Igreja dos apóstolos e a Igreja de Constantino, o Grande (306-377), e seus sucessores" (ARNALDI, 2002, p. 567).

Diante do cenário apresentado, a seguir analisa-se tópico a tópico as principais contribuições do direito canônico para o Direito moderno.

\subsection{Instituto da Pessoa Jurídica}

Foi durante a Idade Média, notadamente no século XIV, que os glosadores e canonistas chegaram ao núcleo central do conceito de pessoa jurídica, partindo das suas exegeses à margem de textos romanos do período pós-clássico, do direito germânico e do próprio direito canônico, tendo este último, sem dúvida, exercido grande e decisiva influência na construção da teoria da pessoa jurídica?.

\footnotetext{
7 AA.VV. Código de Derecho Canónico. Salamanca, BAC, 1999.

8 PALMA, R. F. Introdução do direito. 4.ed. São Paulo: Saraiva, 2010. (e-book)

${ }^{9}$ CAPPEllini, Ernesto (Org.). Problemas e perspectivas de Direito Canônico. (Trad. de Luís João GAIO). São Paulo, Loyola, 1995.
} 


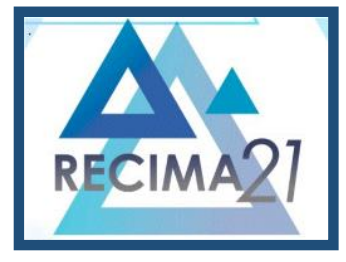

\title{
RECIMA21 - REVISTA CIENTÍFICA MULTIDISCIPLINAR ISSN 2675-6218
}

A necessidade de se estabelecer a natureza da Eclésia, diferenciando-a de seus seguidores, conduziu os canonistas a certas distinções básicas e ao conceito de pessoa jurídica. Os fiéis estavam na Igreja, mas não eram a Igreja. Esta seria um corpus mysticum, ao mesmo tempo com existência material sensível e que não se confundia com os seus membros que nela momentaneamente se encontravam. Os fiéis poderiam até sumir que a lgreja continuaria existindo, pois, o principal era o patrimônio constituído pelos bens necessários à realização dos objetivos a que a Igreja se propunha.

Foi o direito canônico, também o responsável pelo desenvolvimento do instituto da pessoa jurídica. Através do incremento das fundações, então denominadas corpus mysticum, qualquer ofício eclesiástico, provido de patrimônio próprio, era considerado ente autônomo ${ }^{10}$.

O termo tem sua origem no jusnaturalismo que invocava o direito natural para justificar a existência de corpos ou entes morais intermediários entre o Estado e o indivíduo, amparados e nascidos espontaneamente da vontade humana e cuja existência era independente do reconhecimento estatal ${ }^{11}$.

Assim, no dizer de Alves ${ }^{12}$, é com a doutrina jurídica alemã que efetivamente surge a moderna concepção de pessoa jurídica. Ao sistematizarem a matéria civil, os alemães buscaram criar uma teoria capaz de ser aplicada em qualquer ramo do direito:

\begin{abstract}
"Coube à doutrina alemã, nas obras de juristas como Otto von Gierke, Rudolf von Ihering, Kohler, Oertmannn, Zitelmann, formular a moderna concepção da pessoa jurídica. Ao sistematizarem a matéria civil, preocuparam-se em elaborar uma teoria que pudesse ser aplicada em qualquer ramo do direito, considerando a existência de sujeitos de direitos distintos da pessoa natural e lhes atribuindo a titularidade de direitos subjetivos. Partindo da premissa de que o ordenamento jurídico não pode negar a presença concreta de grupos humanos e de bens destinados à satisfação de interesses e necessidades coletivas, dotados de individualidade própria e autônoma diante de seus componentes, impõe-se o reconhecimento pelo direito destes entes, outorgando-lhes atributo que até então só era conferido ao homem, possibilitando o exercício em nome próprio de direitos subjetivos e de deveres". ${ }^{13}$
\end{abstract}

Dessa forma, a pessoa jurídica aparece como uma coletividade de pessoas ou de bens, sistematizada e organizada para a consecução de fins comuns específicos, com individualidade e autonomia próprias, sempre observando a liceidade jurídica e moral de propósitos.

Poucos problemas fomentaram tanto as teorias e as concepções filosóficas como a natureza da pessoa jurídica. A sua conceituação é por demais polêmica, suscitando, ao longo do tempo, divergências doutrinárias e variados entendimentos. Para alguns autores, sob o ponto de vista prático, a solução do problema da natureza desses entes carece de maior interesse, uma

\footnotetext{
10 CAPPELlinI, Ernesto (Org.). Problemas e perspectivas de Direito Canônico. (Trad. de Luís João GaIO). São Paulo, Loyola, 1995.

11 BITTAR, Eduardo C. B. (Org.). História do direito brasileiro. 3.ed. São Paulo: Atlas, 2013. (e-book)

12 ALVES, José Carlos Moreira. Direito romano. 15.ed. Rio de Janeiro: Grupo Gen, 2012. (e-book)

${ }^{13}$ ALVES, José Carlos Moreira. Direito romano. 15.ed. Rio de Janeiro: Grupo Gen, 2012, p. 111.
} 


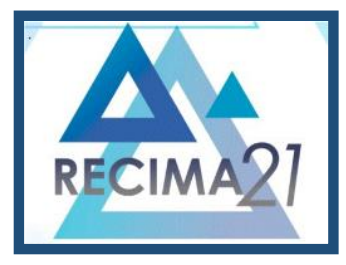

\section{RECIMA21 - REVISTA CIENTÍFICA MULTIDISCIPLINAR ISSN 2675-6218}

vez que nenhuma influência decisiva exerce na construção técnica hoje incorporada às legislações ${ }^{14}$.

As especulações em torno do assunto pertencem antes ao campo da Filosofia do Direito, onde, aliás, vão perdendo substância.

\subsection{Matrimônio}

A descrição histórica da família possui diversos significados. Dependendo do entendimento da expressão, por exemplo, os primeiros grupamentos humanos podem ser considerados organizações familiares, porquanto a reunião de pessoas com a finalidade de formação de uma coletividade de proteção recíproca, produção e/ou reprodução já propiciava o desenvolvimento do afeto e da busca da completude existencial.

Entretanto, a migração de um período de satisfação individual das necessidades básicas de comida, bebida, sono e sexo para a construção de um conglomerado de pessoas que se identificassem reciprocamente como integrantes de uma efetiva coletividade (e não de um mero agrupamento de individualidades) representou a base para o reconhecimento de uma família ${ }^{15}$.

Antes da formação da "família romanista", as tentativas de verificação histórica se embasam em duas interpretações. A primeira, não tradicional, enxerga a família originária como uma família comunal, traduzida em uma comunidade sem restrições de parentesco e sem a autoridade central do pai, um modelo de família que se encerra com a formação do Estado e com o estatuto da propriedade privada ${ }^{16}$.

Encontra nos períodos mais primitivos a presença do matriarcado, o parentesco da linhagem feminina, que não derivava exclusivamente da supremacia abstrata da mulher, mas, sim, de uma circunstância bastante concreta, na medida em que era a mulher quem se ocupava da organização familiar e da economia doméstica.

A análise dos registros históricos, dos monumentos literários e dos fragmentos jurídicos demonstra que a família ocidental viveu um grande período sob a forma patriarcal. Assim foi reconhecida nas civilizações mediterrâneas, nas civilizações romanas e nas documentações bíblicas ${ }^{17}$.

Em Roma, a família era estruturada a partir do princípio da autoridade e abrangia todos aqueles que a ela estavam submetidos, sendo organizada, também, em razão da ideia religiosa:

\footnotetext{
${ }^{14}$ CAPPELLINI, Ernesto (Org.). Problemas e perspectivas de Direito Canônico. (Trad. de Luís João GAIO). São Paulo, Loyola, 1995.

15 GAGLIANO, Pablo Stolze; PAMPLONA FILHO, Rodolfo. Novo Curso de Direito Civil. São Paulo: Saraiva, 2011. v. VI.

${ }^{16}$ CAPPElLINI, Ernesto (Org.). Problemas e perspectivas de Direito Canônico. (Trad. de Luís João GAIO). São Paulo, Loyola, 1995.

17 PEREIRA, Rodrigo da Cunha. Princípios fundamentais norteadores do direito de família. 3. ed. São Paulo: Saraiva, 2013.
} 


\section{RECIMA21 - REVISTA CIENTÍFICA MULTIDISCIPLINAR ISSN 2675-6218}

AS CONTRIBUIÇÕES DO DIREITO CANÔNICO PARA O DIREITO ROMANO E SUAS INFLUÊNCIAS ATUAIS José Antonio da Silva

O pater era, ao mesmo tempo, chefe político, sacerdote e juiz. Comandava, oficiava o culto dos deuses domésticos (penates) e distribuía justiça. Exercia sobre os filhos direito de vida e de morte (ius vitae ac necis), podia impor-lhes pena corporal, vendê-los, tirar-lhes a vida. A mulher viviain loco filiae, totalmente subordinada à autoridade marital (in manu mariti), nunca adquirindo autonomia, pois que passava da condição de filha à de esposa, sem alteração na sua capacidade; não tinha direitos próprios[... $]^{18}$

A família era orientada como uma unidade econômica, política, militar e religiosa, comandada sempre por um indivíduo do sexo masculino, o pater famílias, que era o ascendente mais velho de determinado núcleo, reunindo os descendentes sob sua absoluta autoridade ${ }^{19}$. Pouco importando a idade ou a convolação de matrimônio, todos os descendentes continuavam a Ihe dever respeito e obediência, permanecendo o pater como o chefe do agrupamento familiar até seu falecimento. Nessa época, o critério predominante na estipulação do parentesco não era a consanguinidade, mas a sujeição ao pater famílias.

Ao longo do tempo, as regras severas do Direito Romano foram sendo alvo de flexibilizações. Houve o surgimento do casamento e as necessidades militares impulsionaram a criação de patrimônio independente para os filhos, constituído pelos bens adquiridos como soldados, recebidos no exercício de atividades intelectuais, artísticas ou funcionais ou havidos de forma diversa. Segundo Pereira ${ }^{20}$ :

A partir do século IV o Direito Romano passa a vivenciar uma concepção cristã de família, em que as preocupações de natureza moral preponderam, com base na inspiração do espírito de caridade, sacrificando parte da autoridade do pater famílias, mas conservando seu caráter autocrático.

Ao longo da Idade Média, as relações familiares eram reguladas exclusivamente pelo Direito Canônico, sendo o casamento religioso o único conhecido. Ainda que as normas romanas continuassem a desempenhar grande influência quanto ao pátrio poder e às relações patrimoniais entre os cônjuges, era possível notar a crescente presença de diversas regras de origem germânica ${ }^{21}$.

Em sua evolução pós-romana, a entidade familiar recebeu influência do Direito Germânico, de forma "a abranger a espiritualidade cristã e a reduzir o grupo familiar aos pais e filhos, assumindo caráter sacramental"22. Com a derrocada do Império Romano e o crescimento do Cristianismo, houve uma gradativa modificação do significado da família ${ }^{23}$.

\footnotetext{
18 Idem.

19 Cavalcante, Hugo. A legislação universal extrajudicial do Código de Direito Canônico. São Paulo, Loyola, 2010.

20 PEREIRA, Rodrigo da Cunha. Princípios fundamentais norteadores do direito de família. 3. ed. São Paulo: Saraiva, 2013, p. 31.

21 DINIZ, M. H. Compêndio de introdução a ciência do direito: introdução a teoria geral do direito. 23. ed. São Paulo: Saraiva, 2012.

22 PEREIRA, Rodrigo da Cunha. Princípios fundamentais norteadores do direito de família. 3. ed. São Paulo: Saraiva, 2013, p. 32.

23 GAGLIANO, Pablo Stolze; PAMPLONA FILHO, Rodolfo. Novo Curso de Direito Civil. São Paulo: Saraiva, 2011. V. VI.
} 


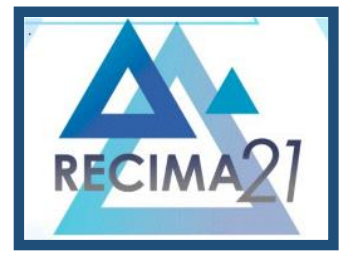

\section{RECIMA21 - REVISTA CIENTÍFICA MULTIDISCIPLINAR ISSN 2675-6218}

Baseada essencialmente no matrimônio, que de situação de fato foi alçado à condição de sacramento, "[...] tal modelo se tornou hegemônico na sociedade ocidental, passando da Antiguidade para a Idade Média, até chegar à Idade Moderna, marginalizando potencialmente outras modalidades de composição familiar"24.

Vale ressaltar que, com o advento do cristianismo, houve uma evolução da ideia de renúncia às relações sexuais completas e mistas em favor do casamento, bem como a negação da institucionalização do divórcio e à realização de um segundo matrimônio, salvo no caso de morte de um dos cônjuges ou da existência do adultério. "Com isso, mostrou-se presente a valorização da família constituída por intermédio do casamento" 25 .

A família cristã representou o formato dominante por séculos, até que com a chegada da Revolução Industrial, em meados do século XVIII, uma nova alteração começou a se efetivar nas entidades familiares, visto que sua visão clássica, centrada no pai de família como líder espiritual e provedor necessário do lar, sofreu grande abalo com os novos anseios da coletividade ${ }^{26}$.

$\mathrm{Na}$ Idade Contemporânea, a família variou em razão do regime econômico do período histórico. Com isso, "na sociedade eminentemente agrária, em que o trabalho era realizado pela célula familiar, a autoridade dos pais era preservada, assim como a convivência entre pais e filhos e própria unidade da família" ${ }^{27}$.

Em uma sociedade conservadora, para obterem a devida aceitação social e o reconhecimento jurídico, os vínculos afetivos precisavam ser ratificados pelo matrimônio. A família representava uma verdadeira comunidade rural, composta por todos os parentes, significando uma unidade de produção com amplo incentivo à procriação. Como a família traduzia uma entidade patrimonializada, seus integrantes consistiam em força de trabalho.

O crescimento da família implicava melhores condições na sobrevivência de todos. A organização familiar era dotada, ainda, de um perfil hierarquizado e patriarcal.

\subsection{Direitos Reais e Pessoais}

É importante uma análise nesse sentido para delinear a natureza dos direitos de crédito. Contudo, trata-se de uma questão recente, já que no direito romano clássico não havia quaisquer preocupações em elaborar uma teoria dos direitos reais, pois não se falava em direitos, mas em ações; consequentemente; a actio precedeu o jus ${ }^{28}$, tanto que os termos jus in re e jus ad rem,

\footnotetext{
24 Idem.

25 DINIZ, M. H. Compêndio de introdução a ciência do direito: introdução a teoria geral do direito. 23. ed. São Paulo: Saraiva, 2012, p. 26.

26 SAMPEL, Edson Luiz. Introdução ao Direito Canônico. São Paulo: LTR, 2001.

27 DINIZ, M. H. Compêndio de introdução a ciência do direito: introdução a teoria geral do direito. 23. ed. São Paulo: Saraiva, 2012, p. 12.

$28 \mathrm{~A}$ actio é a atividade autorizada que se desenvolve na busca de um interesse. Este é suscetível de consistir na dominação total ou parcial de um objeto determinado, caso em que a 'actio' opera e atua 'in rem', ou pode exercitar-se em face de outro sujeito de direito.
} 


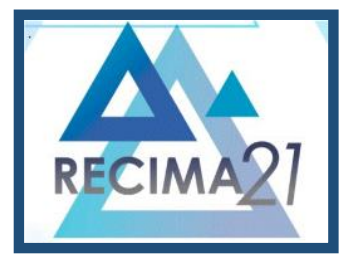

\section{RECIMA21 - REVISTA CIENTÍFICA MULTIDISCIPLINAR ISSN 2675-6218}

utilizados para distinguir os direitos reais das pessoas, apareceram no século XII por influência do direito canônico ${ }^{29}$.

A determinação dos direitos obrigacionais traz um grande número de controvérsias atinentes às suas relações com os direitos reais, no sentido de se constituírem dois institutos idênticos ou de natureza diversa. Com isso consolidou-se a noção de jus in re como algo diverso da obligatio e o jus ad rem passou a ser considerado como uma figura híbrida, por interpor-se entre àquela e o jus in re, criando uma espécie de zona cinzenta entre duas relações. O direito moderno passou, então, a consagrar essa distinção, assinalando as seguintes diferenças entre direitos reais e pessoais ${ }^{30}$.

A noção de contrato está ligada à vontade das partes, ou seja, à liberdade de manifestação de vontade, pois em princípio as pessoas são livres para vincular sua vontade ao cumprimento de determinada obrigação à qual eventualmente se tenham obrigado. Destarte, o consenso de vontades fundado na livre manifestação da vontade constitui o fundamento do contrato, de maneira que o consenso livremente exarado pelos contratantes tem força jurídica de vinculá-los de tal modo e força que faz lei entre eles; em outras palavras, pelo contrato, as partes contratantes criam uma lei especial para reger aquela específica relação jurídica.

Ao contrário do que fez com o ato jurídico, no artigo 81 do Código Civil Brasileiro, o legislador pátrio não se preocupou em explicitar o conceito de contrato, transferindo para os doutrinadores a definição desse instituto tão abrangente.

Pode-se definir contrato como uma espécie de negócio jurídico, de natureza bilateral ou plurilateral, dependente, para sua formação, do encontro da vontade das partes, que cria para ambas uma norma jurídica individual reguladora de interesses privados ${ }^{31}$.

Assim sendo, tem ele por fundamento a vontade humana, atuada conforme a ordem jurídica vigente, que Ihe dá força criativa. É norma jurídica individual posto que estabeleça direitos e obrigações, em regra, apenas entre os contratantes.

No nosso sistema legal vigente, o contrato é considerado negócio jurídico bilateral. É de se ressaltar que, ao contrário do Código Civil de 1916, que no art. 81 outorgava o conceito de ato jurídico como sendo todo ato ilícito que tivesse por fim adquirir, resguardar, transferir, modificar ou extinguir direitos, sendo, por conseguinte, também o conceito de contrato, na medida em que todo contrato envolve necessariamente a aquisição, modificação ou extinção de direitos, o Código Civil vigente não conceitua ato e nem negócio jurídico, nos arts. 104 a 114 tão-somente fornecido delimitações para a manifestação das partes que cria, modifica ou extingue direitos - negócio

${ }^{29}$ DINIZ, M. H. Compêndio de introdução a ciência do direito: introdução a teoria geral do direito. 23. ed. São Paulo: Saraiva, 2012.

30 LARA, Lelis. Cadernos de Direito canônico: o direito canônico em cartas. Direito Pastoral. Ano 2, n. 2, Jul/Dez (2004) 33-36.

${ }^{31}$ DINIZ, M. H. Compêndio de introdução a ciência do direito: introdução a teoria geral do direito. 23. ed. São Paulo: Saraiva, 2012, p. 195. 


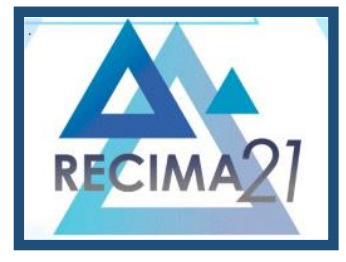

\section{RECIMA21 - REVISTA CIENTÍFICA MULTIDISCIPLINAR ISSN 2675-6218}

jurídico -, não tendo fornecido conceito de ato, negócio jurídico e tampouco de contrato, de forma que tal tarefa foi corretamente relegada à doutrina ${ }^{32}$.

Apesar de o Código Civil haver adotado a teoria da expedição da aceitação do direito canônico, sob o ponto de vista do tempo do contrato, adotou, quanto ao lugar da celebração do mesmo, o da expedição da oferta ${ }^{33}$.

É preciso não olvidar que certas situações especiais e de ordem prática podem exigir a reunião dos direitos obrigacionais aos direitos reais. Verdade seja que os direitos reais não criam obrigações para terceiros, porém em alguns casos importam, para certas pessoas, a necessidade jurídica de não fazer algo. Ante a essa característica, pergunta-se a possibilidade de existência de direitos reais in faciendo, ou seja, de categorias intermediárias entre o direito real e o pessoal. É o que ocorre com as obrigações propter rem, com os ônus e as obrigações com eficácia real, que são figuras híbridas ou ambíguas, constituindo, na aparência, um misto de obrigação e de direito real ${ }^{34}$.

Tais obrigações só existem em razão da detenção ou propriedade da coisa. A força vinculante das obrigações manifesta-se conforme a situação do devedor ante uma coisa, seja como titular do domínio, seja como possuidor. Assim, nesse tipo de obrigação, o devedor é determinado de acordo com sua relação em face de uma coisa, que é conexa com o débito. Infere-se daí que essas obrigações provem sempre de um direito real, impondo-se ao seu titular de tal forma que, se o direito que Ihe deu origem for transmitido, por meio de cessão de crédito, de sub-rogação de sucesso por morte etc. ${ }^{35}$

É uma figura transacional entre o direito real e o pessoal, consistindo num artifício técnico que qualifica uma categoria jurídica que tenha atributos tanto de um como de outro. A obrigação, portanto, está situada entre direito real e o pessoal, já que contém uma relação jurídico-real em que se insere o poder de reclamar certa prestação positiva ou negativa do devedor. É uma obrigação assessória mista por vincular-se a direito real, objetivando uma prestação devido ao seu titular ${ }^{36}$.

As obrigações com eficácia real situam-se no terreno separador entre direitos de crédito para os direitos reais. A obrigação terá eficácia real quando, sem perder seu caráter de direito a uma prestação, se transmite e é oponível a terceiro que adquira direito sobre determinado bem.

Os direitos patrimoniais consistem no conjunto de bens, direitos e obrigações de uma pessoa natural ou jurídica, sendo suscetíveis de estimação pecuniária, dividindo-se em pessoais e reais. Ou seja, é preciso deixar claro que, se os direitos obrigacionais disciplinam relações

\footnotetext{
32 Arbex, Pedro. Teologia Orante na liturgia do Oriente. São Paulo, Editora Ave Maria, 1998.

33 DINIZ, M. H. Compêndio de introdução a ciência do direito: introdução a teoria geral do direito. 23. ed. São Paulo: Saraiva, 2012.

34 DINIZ, M. H. Compêndio de introdução a ciência do direito: introdução a teoria geral do direito. 23. ed. São

Paulo: Saraiva, 2012.

35 SAMPEL, Edson Luiz. Introdução ao Direito Canônico. São Paulo: LTR, 2001.

36 SAMPEL, Edson Luiz. Introdução ao Direito Canônico. São Paulo: LTR, 2001.
} 


\section{RECIMA21 - REVISTA CIENTÍFICA MULTIDISCIPLINAR ISSN 2675-6218}

AS CONTRIBUIÇÕES DO DIREITO CANÔNICO PARA O DIREITO ROMANO E SUAS INFLUÊNCIAS ATUAIS
José Antonio da Silva

jurídicas patrimoniais, que visam prestações de um sujeito em proveito de outro, evidente está que incluem tão somente aos direitos pessoais. Os direitos de crédito regem vínculos patrimoniais entre pessoas, impondo ao devedor o dever de dar, fazer ou não fazer algo no interesse do credor, que passa a ter o direito de exigir tal prestação positiva ou negativa.

\section{CONSIDERAÇÕES FINAIS}

O Direito apresenta-se onde há vida em sociedade e, sendo a Igreja uma organização onde as relações sociais entre seus seguidores são despontadas de diversas maneiras, imprescindível fez-se o nascimento de um ordenamento jurídico característico para atender aos anseios humanos e divinos, nos arquétipos essenciais da própria criação daquela instituição.

Sendo assim, com o desenvolvimento desse trabalho foi possível verificar que são diversas as contribuições do Direito Canônico ao direito ocidental. Desde a Idade Média, o direito em estudo contribui criando institutos jurídicos e cuidando de manifestações sociais e comunitárias de seu interesse, de tal forma, que, em casos, expressa excelência em organização, formalidade e funcionamento. Assim sendo, o Estado em não raros tópicos jurídicos implanta institutos análogos ou diretamente idênticos aos que laboram no ordenamento jurídico eclesiástico.

Não por acaso o Estado influencia-se, em sua organização jurídica, por aquilo que adequadamente funciona no ordenamento jurídico eclesiástico, haja vista que a Igreja agrega milhares de fiéis seguidores e, se as leis desta são capazes de estabelecer, dentro das suas propostas, uma funcional ordem normativa, há de considerarmos natural a atitude estatal de dedicar-se paralelamente, aos seus cidadãos, os mecanismos de ordem que dão fluência à organização eclesial, por fim os indivíduos que vivem sob a égide estatal são, em boa parte, fiéis da Igreja.

\section{REFERÊNCIAS}

AA.VV. Código de Derecho Canónico. Salamanca: BAC, 1999

ALVES, José Carlos Moreira. Direito romano. 15. ed. Rio de Janeiro: Grupo Gen, 2012. E-book

ARBEX, Pedro. Teologia Orante na liturgia do Oriente. São Paulo: Editora Ave Maria, 1998.

BARROS, José D'Assunção. A Cidade Medieval: os grandes debates historiográficos. Rio de Janeiro: CELA, 2003.

BITTAR, Eduardo C. B. (Org.). História do direito brasileiro. 3.ed. São Paulo: Atlas, 2013. Ebook 


\section{RECIMA21 - REVISTA CIENTÍFICA MULTIDISCIPLINAR ISSN 2675-6218}

AS CONTRIBUIÇÕES DO DIREITO CANÔNICO PARA O DIREITO ROMANO E SUAS INFLUÊNCIAS ATUAIS
José Antonio da Silva

CAPPELLINI, Ernesto (Org.). Problemas e perspectivas de Direito Canônico. Tradução de Luís João GAIO). São Paulo: Loyola, 1995.

CASTELLS, Manuel. A Questão urbana. 3. ed. Rio de Janeiro: Paz e Terra, 2006.

CAVALCANTE, Hugo. A legislação universal extrajudicial do Código de Direito Canônico. São Paulo: Loyola, 2010.

DINIZ, M. H. Compêndio de introdução a ciência do direito: introdução a teoria geral do direito. 23. ed. São Paulo: Saraiva, 2012.

GAGLIANO, Pablo Stolze; PAMPLONA FILHO, Rodolfo. Novo Curso de Direito Civil. São Paulo: Saraiva, 2011. v. VI.

LARA, Lelis. Cadernos de Direito canônico: o direito canônico em cartas. Direito Pastoral, Ano 2, n. 2, p. 33-36, jul./dez. 2004.

LOURENCINI, Antônio Rogério. O direito canônico e a formação do direito ocidental moderno: Dos fundamentos do direito canônico à sua geral influência no ordenamento jurídico estatal, mormente no direito de família (matrimônio). Revista Jus Navigandi, Teresina, Ano 19, n. 3919, mar. 2012. Disponível em: https://jus.com.br/artigos/27059. Acesso em: 28 mar. 2021.

PALMA, R. F. Introdução do direito. 4. ed. São Paulo: Saraiva, 2010. E-book

PEREIRA, Rodrigo da Cunha. Princípios fundamentais norteadores do direito de família. 3. ed. São Paulo: Saraiva, 2013.

SAMPEL, Edson Luiz. Introdução ao Direito Canônico. São Paulo: LTR, 2001. 